\title{
Temperature Control Function of the Choroid May Be the Reason for the Increase in Choroidal Thickness during the Acute Phase of Familial Mediterranean Fever
}

\author{
Abdullah Kaya $^{\mathrm{a}}$ Yakup Aksoy $^{\mathrm{b}}$ Mehmet Koray Sevinç ${ }^{\mathrm{c}}$ Oktay Diner $^{\mathrm{d}}$ \\ ${ }^{a}$ Department of Ophthalmology, Anıttepe Military Dispensary, Ankara, Turkey; ${ }^{\mathrm{b}}$ Department of Ophthalmology, \\ Girne Military Hospital, Girne, Cyprus; ' ${ }^{\circ}$ Department of Ophthalmology, Beytepe Military Hospital, Ankara, and \\ ${ }^{\mathrm{d}}$ Department of Ophthalmology, Erzurum Military Hospital, Erzurum, Turkey
}

\section{Dear Editor}

We read the current article entitled 'Choroidal Thickness Changes in the Acute Attack Period in Patients with Familial Mediterranean Fever' by Gundogan et al. [1] with great interest. The authors found choroidal thickness (CT) to be increased during the acute phase of familial Mediterranean fever (FMF). We appreciate the authors for this well organized study and want to make a contribution.

The authors conclude that the reason of increase in CT is inflammatory edematous changes in the choroid. However, there is no evidence about the development of inflammation in the choroid during the acute phase. If there could be an inflammation in the choroid, it would show a clinical presentation like uveitis in Vogt-KoyanagiHarada disease. Thus, we do not agree with the author's conclusion. We hypothesize that the reason for the increase in CT may be the temperature control function of the choroid. The choroid has the strongest blood flow in the body. However, this high blood flow does not correspond to metabolic requirements and is believed to have a role in heat distribution that is generated in the environment of the macula [2]. Body temperature rises during the acute phase of FMF. Thus, the temperature-lowering effect and thereby the blood flow of the choroid is expected increase.

\section{Disclosure Statement}

The authors declare that they have no conflicts of interest.

\section{References}

1 Gundogan FC, Akay F, Uzun S, Ozge G, Toyran S, Genç H: Choroidal thickness changes in the acute attack period in patients with familial Mediterranean fever. Ophthalmologica 2015, DOI: $10.1159 / 000442216$.

$\checkmark 2$ Parver LM, Auker C, Carpenter DO: Choroidal blood flow as a heat dissipating mechanism in the macula. Am J Ophthalmol 1980; 89:641-646.

\section{KARGER}

E-Mail karger@karger.com

www.karger.com/oph
(C) 2016 S. Karger AG, Basel

0030-3755/16/2352-0123\$39.50/0 